\title{
Facial Remodelling and Biomaterial
}

\author{
G. Fini, L.M. Moricca, A. Leonardi, S. Buonaccorsi and V. Pellacchia \\ La Sapienza/ Roma \\ Italy
}

\section{Introduction}

Facial remodelling comprises all the surgical techniques able to reconstruct the correct proportion between soft and hard tissues of the face. In order to obtain facial harmony maxillo-facial surgeons have at disposal many surgical techniques such as reconstructive, orthognatic, aesthetic surgery and camouflage. In the study of a patient who presents facial asymmetry two base evaluations are necessary: aesthetic analysis and cephalometric analysis. The first is an evaluation of the skeleton in association to the evaluation of the soft tissues according to the harmonic proportions of the face, while the second consists in the evaluation of the skeletal relationships with respect to the basicranium through the identification of specific craniometrical points. It is possible to establish a specific therapeutic plan for the specific facial

asymmetry by means of the combination of these analyses and the addition of the radiographies study. There are various pathologies that need facial remodelling: acquired syndromes, congenital syndrome such as the Hemifacial Microsomiae, autoimmune disorder or atrophic disease such as Perry-Romberg Syndrome, traumas, demolitive surgery and infectious pathologies. In these clinical conditions the choice of a therapeutic treatment of camouflage instead of corollary surgery and conventional aesthetics techniques is made when there is a specific request from patients. This decision is also made when there is an increased operative risk and the deficits to fill are not massive. The described surgical treatments present the advantage of being not invasive, easy to position, not much traumatic and with immediate results. The complications can be the following: shifting of the biomaterial , chronic inflammation, quick reabsorption of the used materials, infections and reject. The camoufflage is growing as a surgical technique for the continuos scientific studies, on the new bio-materials. The studied filling bio material are the porous polyethylene and the bio-bone for the hard tissues, the Polyalkylimide and Polyacrylamide for the soft tissues. Some representative clinical cases are presented.

During our experience, patients have been treated with the following bio materials: porous polyethylene, bio-bone, polialkylimide, polyacrylamide, and with a combined treatment with polyacrylamide and porous polyethylene. The patients treated with porous polyethylene presented pathologies deriving $50 \%$ from traumas, $40 \%$ from malformation and a $10 \%$ from congenital asymmetries. The patients treated with bio-bone $(7 \%$ of the total patients) of the total were presented in all cases the bony atrophy of the jaw.

Patients suffering from infectious pathologies (HIV) were included among the patients treated with polialkylimide, others with autoimmune pathologies (PRS) and with malformative syndromes were included too. The treatment with polyacrylamide was 
carried out in patients with autoimmune syndrome (Scl and PRS), LPS results people, HIV affected, and patients with congenital malformation (HMF). We have a diagnostic and therapeutic procedure uniform for all the patients; the first clinical evaluation concerns radiographic and laboratory examination, such as head and neck Dimensional Computed Tomography, Magnetic Resonance, Ultrasonography, Orthopanoramic x-rays, searches for ANA-ENA-Anti Cardiolipina anticorpal; specialized infective and immunologic consulence relating to the single patient has been committed. The $7 \%$ of the patients has been treated with a replenishment composed of the combination with porous polyethylene and polyacrylamide because of the wide loss of both skeleton and soft tissues. Some other representative clinical cases are presented:

\section{Biomaterials}

Polyacrylamide - Clinical Case 1: CC, a female of 17 years old, came in our center for hemifacial hasimmetry. This anomaly wascharacterized by a progressive atrophy of the left hemiface. The patient did not present diplopy. The objective examination we observed the presence of slight atrophy of the left middle and inferior third of the face, including nasolabial region and the omolateral upper lip. A nasal pyramid deviation also appeared and confirmed by the anterior rhynoscopy, which also showed a left-convex deviation of the nasal sept. A Dimensional Computed Tomography scan was performed. This exam confirmed a maxillo- mandibular fault. Then an orthotic evaluation was performed to value muscular structures. We adopted a surgical approach which primarily provided an improvement of the respiratory activity. Then, we planned a filling of the atrophic soft tissues through infiltrations of Polyacrylamide. The infiltrations have been performed after 2 months from the septorhynoplastic surgery. Biomaterial $(5 \mathrm{ml})$ in the left nasolabial fold was filled. After 1 month from the beginning of the treatment, we noticed an evident reduction of the pre-existing deficit of the soft tissues. The clinical and Ultrasonography checks after 2,6, 12 and 24 months confirmed a correct integration of the used biomaterial.

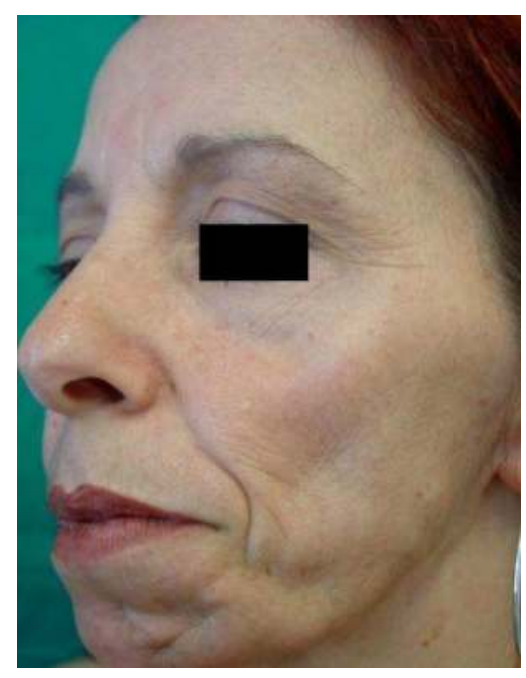

Fig. 1. Lateral view of the patient before treatment 
Clinical case 2: E.M, female of 45 years referred about the appearance of a progressive facial asymmetry alterations interesting the lower third of the face in particular in the last 3 years. The tissue deficit was becoming clearer without any symptoms or alterations in the facial motility. (FIGURE 1) Therefore a Computed Tomography Scan of the face was performed, in order to evaluate the entity of such deficit. It shows marked deficit of the soft tissue, which was extending partially to the skeletal structures". During the objective exam conduced even with a photographic study, the loss of the symmetry was appreciating, in particular to the third lower of the hemiface. Problems related to the function of the facial nerve, were not noticed, and the patient did not refer facial hypoesthesia.

Therefore the patient underwent to fill of the facial soft tissues with biomaterial. The biomaterial was implanted in the left middle and inferior third of the hemiface; moreover it has been noticed a partial resorption of the biomaterial at the end of treatment. A total of 3 infiltration has been performed for a tot of $8 \mathrm{ml}$ of infiltrated biomaterial. (FIGURE 2)

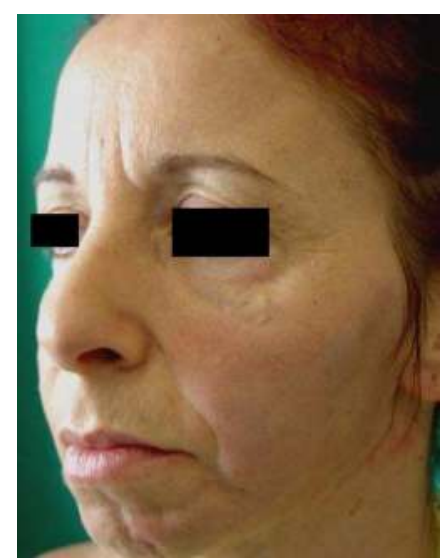

Fig. 2. Lateral view of the patient after treatmet

Clinical Case 3: E.D.E, male of 55 years old, immuno-compromised patient, affected by HIV from 20 year. He had underwent to the Highly Active Anti-Retroviral Therapy treatment (HAART) from about ten years. The patient referred the appearence of an atrophy in the middle third of face, he had developed a lypodistrophy lesion of soft tissues. (FIGURE 3)

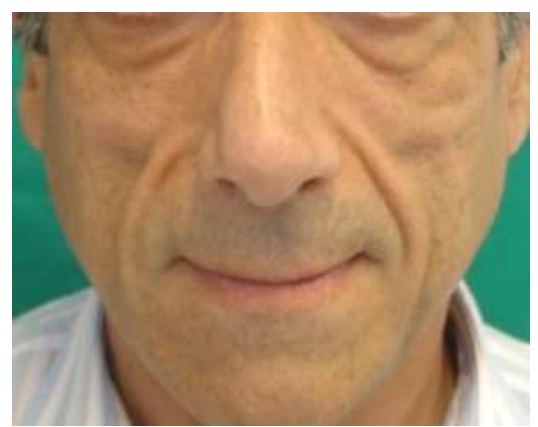

Fig. 3. Particular of the lypodistrophy area 
The patient was stable from clinical and infective point of view, confirmed by hematologic exams; so that we decided to underwent the patient to biomaterial infiltration with Polyacrylamide. The sites of treatment were the areas where the atrophy and the lypodistrophy are happened. Clinical-aesthetic and infective results in six years of follow-up were good. (FIGURE 4)

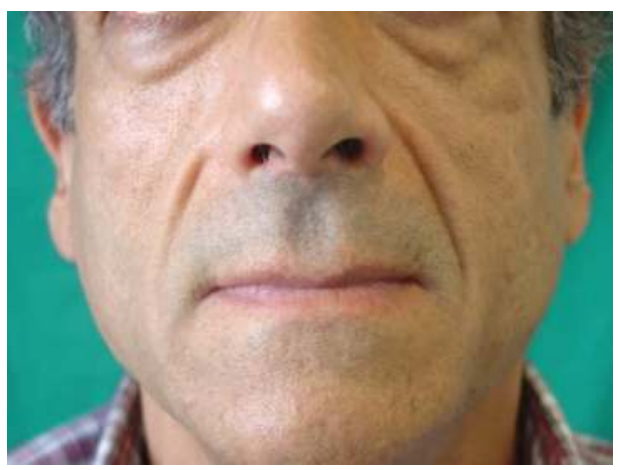

Fig. 4. Particular of the the lypodistrophy area after treatment

Polyalkylimide - Clinical case 4: D.L.B, a male of 30 years old, showed an atrophy of the middle and inferior third of the face. The patient eight years before, referred a not treated facial trauma. The objective exam showed the presence of a moderate atrophy of the rigth hemiface, associated to aesthetic and functional alterations. In particular, a combination of the right orbital-malar asymmetry complex, and a rigth orbital oenophtalmo was noticed as well. 7. The patient referred about the appearance of dyplopia. It has not been well clarifyied. The patient underwent before further clinical and radiological checks exams to study the soft tissues, and to evaluate the ocular motility, so as a Perry Romberg Syndrome was suggested for diagnosis. A surgical treatment was planned to correct the oenophtalmo and to restore the ocular motility correcting the dyplopia disfunction. On the other hand, this surgery has been performed with the goal of resolving the atrophy and the face's deformity through the use of porous polyetilene. Afterwards, a treatment of polyackylimide infiltrations has been planned. The patient, after 1 week from the treatment with biomaterial, presented a good tolerance and a total restoration of the facial eurytmia. An ultrasonographic evaluation was performed to value the integration of the biomaterial after 6,12 and 24 months; this exam showed a compartment of the biomaterial implanted, associated to fibrotyc branches compatible with the basal pathology.

Porous polyethylene - Clinical Case 5: S.B, a female of 40 years old, referred facial asymmetry. The objective exam showed a skletal deformity of mandibular and maxillary component, associated to mycrogenia.(FIGURE 5)

The patient presented a congenital nose deformity too. The surgical treatment was planned with mandibular promotion by means graft of porous polietylene. Then in the same surgical step a graft "on lay" of septal cartilage was positionated on the nasal dorsum. Ultrasonographic checks after 1 month, 23 months and 6 months were optimal; radiologic exams were performed to check the planted biomaterial. These investigations verified a good tolerance and a well fixed of the biomaterial. (FIGURE 6) 


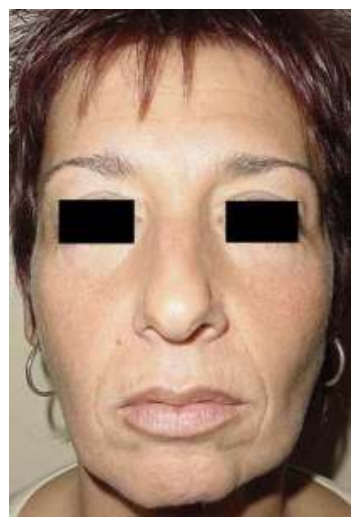

Fig. 5. Frontal view of the patient before treatment

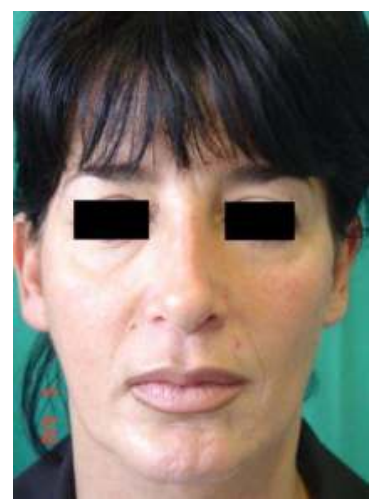

Fig. 6. Frontal view of the patient after treatment

Bio-bone - Clinical case 6: ML, 19 years old female, came up to our attention for a mandibular lesion. It was an occasionally finding of a Magnetic Risonance carried out previously after a lipothymia event. This mandibular 8 lesion was an osteolytic one, positioned in the left ramous under 3.6 to 3.8 roots. Patient had not simpthoms, and the clinical exam didn't show any visible or touchable lesion in the fornix gum, or at the corresponding teeth. Patient only referred a mononucleosis infection six months before. Computed Tomography of the Head and Neck and Orthopanoramic x-rays were carried out (FIGURE 7) .

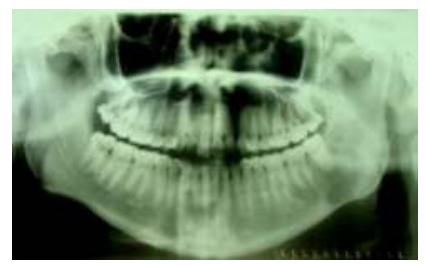

Fig. 7. Pre operative Orthopanoramic x-rays 
These images were likely suggestive for adamantinoma. That hypothesis led to a particular operative interventation with the aim of a definitive diagnosis and treatment. In fact the histologic exam would have led, or not, to a mandibular resection. So left mucous fornix section was performed in order to uncover the mandibular bone from 3.6 to 3.8 dental elements and to dissect the bone through osteotribe, as long as the lesion was found. Strangely enough the surgical finding was a rarefaction of the bone, no capsular structure or any other elements that could help with the diagnosis were observed as well. Consequently a conservative surgical technique was carried on, such as cutting out the bone box with 3.7 and 3.8 because of their roots inclusion in the osteolitic lesion as well. The missing bony part was filled with a demineralized bone matrix, in order to prevent iatrogenic fracture. So before performing a mandibular ramous resection, we have been waiting for the definitive histologic diagnosis. Unfortunately, against every expectation, it resulted as a follicular cyst within Candida A. yeasts. It was performed a batteriologic exam that resulted positive for C. Albicans too and for Hafnia alveii. Antibiotic and antimicotic therapies were carried out for a long period. After three months patient underwent to a Orthopanoramic x-rays, that revealed the biomaterial integration but a surgical interventation of removing bio-bone it was necessary in order to assure the complete eradication of the Candida infection. (FIGURE 8)

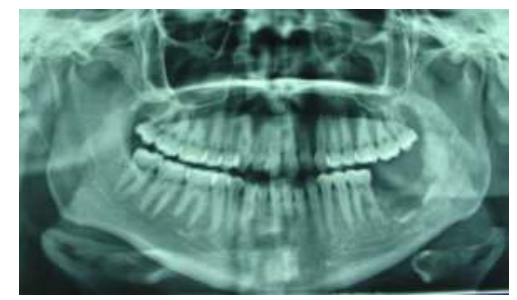

Fig. 8. Post operative Orthopanoramic x-rays

Porouse polyethylene and Polyacrylamide - Clinical case 7: R.A, a male of 40 years old, affected by the Goldenhar syndrome, he underwent to differentreconstructive surgical treatments, to restore the normal symmetry of the face soft tissues. The patient showed a facial asymmetry characterized by an atrophy of the right hemifacial soft tissues, associated to auricular agenesys, and a behind-positioning of the left auricle.(FIGURE 9)

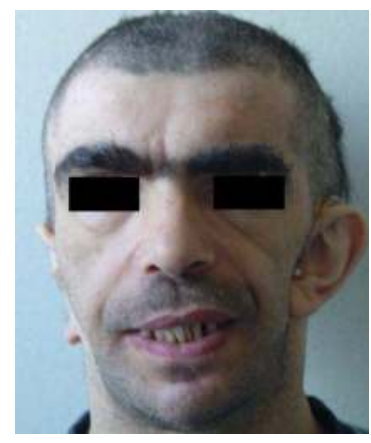

Fig. 9. Frontal view of the patient before treatment 
Radiological and clinical exams with Computer Tomography Dental Scan and Telecranium $x$ ray in two proiections with cefalometric study were performed to evaluet bony and soft tissues. After 1 month surgery was performed: two fixures with abutment have been positioned in the right mastoid bone, Then the left auricular was positionated to restablish the normal structures of the face. In the same surgical time, two porous polyetylene prosthesis were implanted in the malar region, to restore the sagittal diameter of the middle third of the face; other two porous polyetylene prosthesis were implanted on the mandibular angle and one more prosthesis was implated on the sinphisis, to restore the transversal and sagittal diameter of the thrid inferior of face. After three mounths an auricular prosthesis associated to Polyacrylamide implant, was positioned in bilateral preauricular area (FIGURE 10). Clinical and radiological follow-up demonstrated a good integration of implants and the biomaterial.

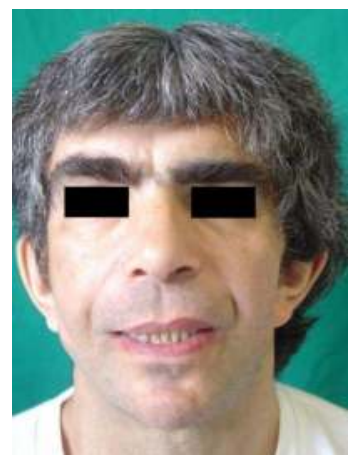

Fig. 10. Frontal view of the patient after treatment

\section{Ultrasonography monitor follow-up}

The ideal biomaterial should be easy to implant and to remove, and simple to be identified by a low-dose radiation and low-cost radiologic technique. Authors wanted to evaluate ultrasonography (US) as a technique in monitoring biomaterial status after operation. Ultrasonography has been shown as an excellent way to visualize clinical features and a possible pathologic process of an implanted biomaterial; it is a non-invasive, low-radiation and low-cost dose radiologic technique. Reconstruction in facial deficit diseases needs adequate biomaterial to implant and a careful patients observation, that is, both clinical and radiologic. Ultrasonography is a fundamental component of the follow up of implanted biomaterial patients. the use of synthetic materials instead of an autolog tissue is codified from years and is widely diffused. In the last years, maxillofacial surgery has adopted poliacrilamide for the soft tissue, which is already used in esthetic surgery such as "last generation filler" to overwhelm the defects of the time such as wrinkles and furrows. Such material has replaced paraffin and silicone fluid used in the 1960s, and collagen and analogs used in the 1980s.In the same years, Conley and Baker experienced some slow-resorption synthetic materials that, when inserted in the derma, overwhelmed cutaneous imperfections. The biomaterials used until that moment were all very well tolerated, but they introduced the disadvantage of being "statics" materials, concrete, and above all, temporary. In the last few years, poliacrilamide has replaced, in part, the use of these 
materials. it does not have these common disadvantages, such as being concrete, visible during activation of mimics muscles, and having a temporary effect. For what concerns the skeletal tissue, for years we have used autologous bone grafts and cartilaginous tissues similar to many prosthetic materials. They showed plastic phenomenon and they were easy to infections and resorption instead of esthetic and functional aspects. In these years, porous polyethylene results to be a suitable material for bony integration; it is easy to use and has great reconstructive quality and low susceptibility to infections. A general problem of the same biomaterials is a lack of visibility on conventional radiographs; they can be seen using magnetic resonance imaging or computed tomography. These investigations are not suitable for the frequent examinations, because magnetic resonance imaging is a high-priced procedure and computed tomography has a high radiation dose. During the follow-up, we encountered some difficulties for their radiotransparency; therefore, in our study, we used a noninvasive technique such as ultrasonography (US) to estimate the filling conditions and eventually to characterize an eventual pathologic process during the early phase. The aim of this study was to examine the use of ultrasound imaging in detecting the changes in biomaterials.

All patients were grouped according to different kinds of diseases: malformative pathologies (patients with hemifacial microsomia), degenerative pathologies ( patients with scleroderma and with Romberg syndrome), results of skull-facial traumas, and pure aesthetic problems such as senile aclasia. They have been examined using US (in early and late postsurgical courses) with a highresolution probe (7.5-13 MHz, Astro; Esaote Biomedica, Genoa, Italy). The protocol of the study has foreseen almost 3 ultrasound controls; with a variable follow-up of 7 days to 36 months. After 7 days ofimplantation, we made the first ultrasound control.

Polyethylene porous, being a semirigid material that needs rigid interns fixture, decreased migration and stabilization problems. The polyacrylamide is introduced as a gel. If it is not well positioned, it could migrate. Integration and migration progress can be studied by US investigations, such as object examination. Initially, in both treated groups, transplant may show a light inflammatory state that will disappear in the succeeding days. Correct evaluation to appraise for the stabilization of the materials is composed of evaluating clinical and US parameters. The clinical parameters were as follows: the alteration absence of the impending fabrics, the graft, the edema absence, manque' mobilization, or migration of the implantation. The US parameters were as follows: absence of massive harvests of liquidate, inflammatory reactions of the surrounding fabrics, and good visualization of the implantation and the surrounding tissue. With this worktop, we have been able to appraise the diverged characteristics of the biomaterial and visualize the tissues reactions. In our results porous polyetylene showed strong ecogenic features such as the bone and vanishing margins; however, the implantation (like a titanium screw) appears as a reverberated ultrasound bundle. We could evidence the stability of the biomaterials, namely, its integration, eventual nearby tissue alterations, in the early and late phases. Therefore, polyacrilamide appears anecogenous with a water-like aspect in the recent implants and corpuscolated in the older ones. Sometimes, such as in connective tissue degenerative pathologies (such as scleroderma) with an increase of the fibrotic component, we can visualize more vacuolized structures not for a lack of fibrotic integration but for the pathologic fibrotic beams. Although the implant seemed to be surrounded by a fibrotic tissue envelope, US technique can be considered an excellent way to visualize the clinical 
features and the pathologic process of implanted biomaterials. It represents a low-cost and low-radiation dose technique for a careful follow-up of patients affected by facial deficit disease after biomaterial implantation. The US technique shows a high radiologic sensibility in evaluating the features of the biomaterials. For its use, the limited cost and lack of investigation on harmful US is the key for studying of the biomaterials. (18)

\section{Discussion}

A biomaterial is defined as a several composed structure, able to interface with the biological systems in order to increase the volume, to give support or to replace a tissue. The performances of the installed materials are evaluated on the basis of bio-functionality and bio-availability therefore bio-compatibility (1).

The bio-functionality is the property of a bio-material to produce a determinate function from the physical and mechanical point of view while the bio-availability is the capacity of a bio-material to develop a determinate function during all the useful life of the plant (2). The final properties of a material depend both on the intrinsic molecular structure of the polymer and on the chemical and physiques processes to which it is exposed and can be widely manipulated intervening on the 10 operating conditions of such processes and on the polimerizzation's reaction. The immediate answers of the human body to the action of a biomaterial is divided in two phases: an inflammation is initially developed because of the first defensive reaction of the organism to an foreign body; subsequently there is a restorative process of the damage. In general if the installed material is toxic, this causes the necrosys of the surrounding tissues; if it is not toxic and inert under the biological point of view a fibrous capsule around to the plant is formed (this answer is quite rare because the biomaterial is usually not completely inert); if, at last, the material is bioactive, it stimulates a precise biological answer and it is progressively supplemented with the surrounding tissue.

In most cases the material undergone some degradation form and the products of such process are released in the tissues. Such products, if they are not biologically active and they are not toxic, are removed with the normal metabolic processes, if however their concentration reaches high values they can locally accumulate and give an acute or chronic pathologies .In case, instead, of toxic products, a persistent inflammation developed; the products of the degradation processes, can stay in the releasing zone, with only local effects, or they can spread in the vascolare system and have so effects also on organs and tissues far from the releasing zone. The progress of the medical research has allowed the perfectioning and the development of new biomaterial in the reconstructive surgery, that has aesthetic licence to obtain excellent results by no much invasive surgical techniques and immediate results. An ideal bio-material presents these characteristics: absence of toxicities, anti-allergic properties, bio-compatibility (2), biofunctionality, easy to use and easy to remove. In our study the porous polyethylene and the bio bone have been analysed as substitutive of the hard tissues and the polyacrylamide and polialkylimide for the soft tissues (3). The bony reintegration is a complex and multi-factory process studied end analyzes in the time (4). At present several substitutive alternatives of the bone by autologus and eterologus bone, biomaterial are possible. Since the past what better choice was considered the allograft bone (5-6) which was useful for replacement of big bony deficits even if with difficult 11 vascularization $(16-50 \%$ of fractures)(7). The bone-conductive, mechanical and 
immunological properties were good but correlated to the seat of the withdrawal and to the type of bone processing (5-7-8-9). The Demineralized Bone Matrix can be easily extracted with 0.5 or 0.6 NHCL $(\mathbf{1 0 - 1 1 )}$

from the allograft bone so as to obtain an increase in the bone-inductive capacities, the loss of the immunological power and an increase in his supplementary effectiveness (12). One of the limits of the Demineralized Bone Matrix is his malleable consistency which makes him suitable for the bony filling most than to the bony replacement, above all in districts of the face that is not subject to the traction of the soft tissues (13). Everybody notice the porous polyethylene, used for the reconstruction of the hard tissues of the face; This material presents bio-compatibility with the human organism and easy malleability (14). This includes that the surgical time are considerably reduced and the surgical procedure are not much invasive. One of the advantages of this material is his property to restore big bony deficits, contributing to give volume to the absent structures . It is fixed by screws, which contribute to the maintenance of a fixes position in the time, as it is also taken back in literature (15). His utilization can be corollary of the orthognathic surgery in the restoration of the facial harmony or in the treatment of facial asymmetries from pathologies.Sharpen for this big variety of applications the porous polyethylene exists in various forms concerning the various facial places to restore: orbital margin (15), nasal dorsum, mandibular ramus. The injectable filler are very commonly used for the treatment of soft alterations of the tissues of the face; these can be of different nature and composition. Are commonly divided in temporary and permanent; in our work take the permanent filler into consideration like the plyacrylamide and polialkylimide. These are also defined of the "hidrogel", for the high water content; their use has prevalently aimed at the filling of soft tissues, whit satisfactory results. Their principal properties are: elasticity, permeability and high bio-compatibility with the organism. Of these we remember the polialkylimide, injective bio-material formed by $2.5 \%$ of synthetic polymer of polyalkylimide and for $97.5 \%$ from apirogen water. Studies have been also executed in 12 vitro and they have shown a low toxicity and cutaneous sensibilization, following prolonged treatment. The polyacrilyamide (16- 17) is an injectable bio- material, formed by $3 \%$ of reticulate polymer of polyacrylamide and $97 \%$ from not pirogenic water. It is an hydrophilus absorbent gel, what comes infiltrated in deficit of the soft tissue. His mechanism of action is to add volume to the soft tissues, restoring the normal structures of the face. This bio material has an easy applicability also in different pathologies; important is not to use in post herpetic phase. It needs several applications for the partial absorption which can verify.

\section{Results and conclusion}

The study's results, based on our experience, have been more than satisfactory. The 290 treated patients, have given optimum results to a 6 year follow up. And also true that the experience acquired during the years about the porous polyethylene is previous of 12 years from the beginning of our study, that is happened in 2000. The justify for which in such work we considered the patient treated from this date, is due to the fact that before we did not have a sufficient sample of patient treated with other filling biomaterial to compare with porous polyethylene already mentioned. In aesthetics surgery the new fillers got rich of greater biological qualities and of easy utilization and their application has made possible for various infectious, malformativ or post-traumatic pathologies. This comparison has been optimum, in the perspective of a patient's better management and treatment of the deficits 
of the facial soft tissue: in order to choise the biomaterial as much as more suitable and-bio compatible with the host organism. To a careful evaluation of every single case, the results have not been completely uniforms; in the patients treated with polialkylimide, adverse reactions have happened: in two cases has verified a multi-capsule formations around the biomaterial, with relative capsule formation and an only case the rejection, with adverse cutaneous reaction. In particular the case of rejection has verified in subject with Hemi-facial atrophy. The phenomenon of compartimentalizzazione was verified in only two cases, it was not due to the absence of integration of the biomaterial with the organism but it was consequent to the 13 autoimmune pathology. For the subjects treated with polyacrilyamide adverse reactions have not happened; the material has shown a good integration in patients with various pathologies. This biomaterial turns out to be of easier utilization and provided with greater fluidity injection. For what concerns the patients affected with infectious pathologies like HIV, their treatment with filling biomaterial has given both recent and after 3 year distance good results; rejection events have not happened. Such patients are constantly evaluated by the infective point of view; we have experiences of biomaterial's utilization in HIV+ patients with HAART treatment which present lipodystrophy lesions . The malleability and easy application of the hydrogel, an utilization of theirs has made possible in combination to other biomateriali. The use of different biomaterials in the same patient is necessary when the deficit to fill was high and when the simple application of an only one biomaterial was turning out insufficient. The treated cases have given good results and good tolerance between the installed material. Porous polyethylene, bio-bone, Polyalkylimide, Polyacrylamide offer a good alternative in selected cases to the traditional reconstructive surgery, for the immediate results and easy way of application. A follow up of at last six years through echography and Computed Tomography exams shows their biocompatibility, stability and inactivity, The restoring of symmetry and harmony of a face can be reached through both traditional surgery and also using biomaterials, that can substitute tissues graft or osteotomy with an easy way of application, their stability and their long lasting, not last a good esthetic result.14

\section{References}

Bulbulian AH. Maxillofacial prosthetics: evolution and practical application in patient rehabilitation. J Prosthet Dent 1965; 15:554Y569

Fini Hatzikiriakos G. Uno sguardo al passato, curiosita' sulle protesi nasali. Il Valsala 1985;61:61Y64

Tjellstrom A. Osteointegrated implants for replacement of absent or defective ears. Clin Plast Surg 1990;17:355Y366

Tjellstrom A, Granstrom G. One stage procedure to establish osteointegration: a zero to five years follow-up report. J Laryngol Otol 1995;109:593Y598

Schaaf NG. Maxillofacial prosthetics and the head and neck cancer patients. Cancer 1984;54:2682Y2690

Labbe' D, Be'nateau H, Compe`re JF, et al. Implants extra-oraux: indications et contreindications. Rev Stomatol Chir Maxillofac 2001;102:239Y242

Be'nateau H, Crasson F, Labbe' D, et al. Implants extra-oraux et irradiation: tendances actuelles. Rev Stomatol Chir Maxillofac 2001;102:266Y269

Granstrom G, Jacobsson M, Tjellstrom A. Titanium implants in irradiated tissue: benefits from hyperbaric oxygenation. Int J Oral Maxillofac Implants 1992;7:15Y25 
Markt JC, Lemon JC. Extraoral maxillofacial prosthetic rehabilitation at the M.D. Anderson Cancer Center: a survey of patient attitudes and opinions. J Prosthet Dent 2001;85:608Y613

Tjellstrom A, Granstrom G. One-stage procedure to establish osteointegration: a zero to five years follow-up report. J Laryngol Otol 1995;109:593Y598

Ramires PA, Miccoli MA, Panzarini E, Dini L, Protopapa C. In vitro and in vivo biocompatility of a Polylkymide Hydrogel for soft tissue augmentation. J.Biomed.Mater.Res.Part.2004; 72: 230-238. 2004.

Christensen LC, Breiting VB, Aasted A, Jorgensen A, Kebuladze I. Long-Term effects ofpolyacrylamide hydrogel in human breast tissue. Plast.Reconstr.Surg.2003; 11:1883-1890

Rees TD, Ashlet FL, Delgado JP. Silicone fluid injectons for facial atrophy: a 10 years study.Plast.Reconstr.Surgery. 1985;52: 118-125.

Greenwald AS,bBoden SD, goldberg VM et al.Bone graft substitutes: Facts, fictions and applications. J. Bone Joint Surg Am 2001; 83-A:S98-S103

Bauer TW, Muschler GF. Bone Graft Materials. An overview of The basic scienze. Clin Orthop. 2000; 371:10-27.

Oka Y, Ikeda M. Treatment of severe osteochondritis dissecans of the elbow using osteochondral grafts from a rib. J Bone Joint Surg Am. 2001 83-b: 738-739

Stevenson S. Biology of bone grafts. Orthoped Clin North Am. 1999; 30:543-552.

Skowronski PP, An Yh. Bone graft materials in orthopaedics.MUSC Orthopaed J. 2003;6:58-66

Betz RR. Limitation of autograft and allograft: new synthetic solutions. Orthopedics 2002;25(Suppl):S561-S560

Hollinger JO, Mark DE, Goco P, et al. A comparison of four particulate bone derivatives. Clin

Pietrzak WS, MillervSD, Kucharzyk DW, et al. Demineralized bone graftvformulations: Design, development, and a novel exemple. Proceedings of the Pittsburg BonevSymposium, Pittsburgh, PA, August 19-23,"003,557-575.

Davy DT.Biomechanical issues in bone transplantation. Orthop Clin North Am.1999;30:55356 science and technology for the Craniomaxillofacial Surgeon.J Craniofac. Surg. 005(16);6:981-988.15

Mauriello JA, McShane R, Voglino J. Use Vicryl( Polyglactina 910) mesh implant for correcting enophtalmos A study of 16 patients. Ophthal Plast Reconstr Surg 1990; 6:247-251.

S. Ozturk, M Sengezer, S Isik et all. Long Term Outcomes of Ultra Thin Porous Polyethylene Implants used for Reconstruction of Orbital Floor Defects. J Craniofac Surg. 2005 (16) 6:973-977.

S. Buelow, D Heimburg, N. Pallua. Efficacy ad Safety of Polycrylamide Hydrogel for Facial Soft-Tissue Augmentation. Plast Reconstr Surg 2005 (15);1137-1146. KW Broder, SR Cohen. An Overview of Permanent and Semipermanent Fillers. Plast Reconstr Surg 2006 118(3 suppl.) S7_S14 Biomaterial Implantation in Facial Esthetic Diseases: Ultrasonography Monitor Follow-Up

Elena Indrizzi, MDS, Luca Maria Moricca, MD, Valentina Pellacchia, MD,

Alessandra Leonardi, MD, Sara Buonaccorsi, MD, Giuseppina Fini, MDS, PhD. The Journal of Craniofacial Surgery -Vol.19, N. 4 -July 2008 


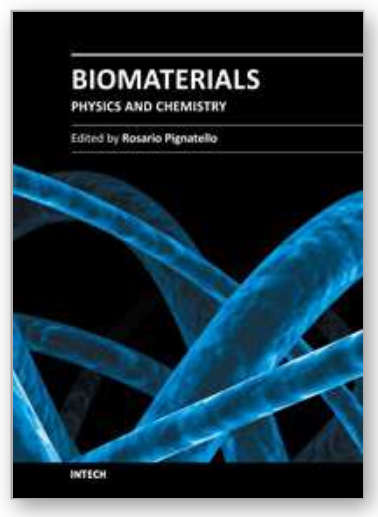

\author{
Biomaterials - Physics and Chemistry \\ Edited by Prof. Rosario Pignatello
}

ISBN 978-953-307-418-4

Hard cover, 490 pages

Publisher InTech

Published online 14, November, 2011

Published in print edition November, 2011

These contribution books collect reviews and original articles from eminent experts working in the interdisciplinary arena of biomaterial development and use. From their direct and recent experience, the readers can achieve a wide vision on the new and ongoing potentialities of different synthetic and engineered biomaterials. Contributions were selected not based on a direct market or clinical interest, but based on results coming from very fundamental studies. This too will allow to gain a more general view of what and how the various biomaterials can do and work for, along with the methodologies necessary to design, develop and characterize them, without the restrictions necessarily imposed by industrial or profit concerns. The chapters have been arranged to give readers an organized view of this research area. In particular, this book contains 25 chapters related to recent researches on new and known materials, with a particular attention to their physical, mechanical and chemical characterization, along with biocompatibility and hystopathological studies. Readers will be guided inside the range of disciplines and design methodologies used to develope biomaterials possessing the physical and biological properties needed for specific medical and clinical applications.

\title{
How to reference
}

In order to correctly reference this scholarly work, feel free to copy and paste the following:

G. Fini, L.M. Moricca, A. Leonardi, S. Buonaccorsi and V. Pellacchia (2011). Facial Remodelling and Biomaterial, Biomaterials - Physics and Chemistry, Prof. Rosario Pignatello (Ed.), ISBN: 978-953-307-418-4, InTech, Available from: http://www.intechopen.com/books/biomaterials-physics-and-chemistry/facialremodelling-and-biomaterial

\section{INTECH}

open science | open minds

\section{InTech Europe}

University Campus STeP Ri

Slavka Krautzeka 83/A

51000 Rijeka, Croatia

Phone: +385 (51) 770447

Fax: +385 (51) 686166

www.intechopen.com

\section{InTech China}

Unit 405, Office Block, Hotel Equatorial Shanghai

No.65, Yan An Road (West), Shanghai, 200040, China 中国上海市延安西路65号上海国际贵都大饭店办公楼 405 单元

Phone: +86-21-62489820

Fax: $+86-21-62489821$ 
(C) 2011 The Author(s). Licensee IntechOpen. This is an open access article distributed under the terms of the Creative Commons Attribution 3.0 License, which permits unrestricted use, distribution, and reproduction in any medium, provided the original work is properly cited. 